\title{
MULTI-OBJECTIVE OPTIMIZATION FOR OPTIMAL HYBRID RENEWABLE ENERGY SOURCE SELECTION IN HYBRID RENEWABLE ENERGY SYSTEMS
}

\author{
${ }^{1}$ Shilaja C, ${ }^{2}$ Dr.S.Jeyanthi \\ ${ }^{1}$ Department of EEE, Kalasalingam Academy of Research and Education, Krishnankoil, India. \\ ${ }^{2}$ Associate Professor, Computer science and Engineering, PSNA College of Engineering and Technology, Dindigul.
}

\begin{abstract}
Power generation is more important to fulfill power demand throughout the world. Population and their electric power demand are increasing day by day. Achieve the energy demand from end-users, and recent research works have concentrated on designing a hybrid energy system. This paper proposed a multi-objective optimized model of a hybrid renewable energy system for a grid. The optimal model can choose a suitable design model of solar, wind, diesel, and batteries interconnected in the hybrid energy system. Optimization is applied for minimizing the system cost, fuel cost and diminish the fuel emission. It also aimed to improve the reliability of renewable sources. Initially, the problem is defined as a multi-objective problem and solved by a multi-objective evolutionary algorithm. From the simulation results, it is identified that the proposed multi-objective evolutionary algorithm performs better.
\end{abstract}

Keywords

Energy Generation, Renewable Energy Sources, Hybrid Energy Generation, Solar System, Wind System, Thermal System. Article Received: 20 September 2020, Revised: 30 November 2020, Accepted: 18 December 2020

\section{Introduction}

Electricity generation is an essential process where it generates electric energy from various primary sources, transmit, distribute, and store. The electric power system is constructed into three significant parts: energy generation, transmission, and distribution. Power generation is the first step where it covert the primary source into electric energy. The primary source is again categorized into renewable and non-renewable sources. The electrical energy conversion obtains different energies from various natural resources like coal, oil, thermal, solar, wind, etc.

Renewable energy sources always provide reusable and sufficient sources frequently. But the non-renewable sources are very limited in nature and not reusable. Some of the nonrenewable energy sources are coal, oil, and gases. Solar, wind, tidal are some of the examples of renewable energy sources. The main concern regarding energy behavior is that we cannot get a considerable amount of energy freely from nature since it needs to be generated by constructing power generation plants.

\section{Solar Energy System (SES)}

SES is one of the best ways to generate power utilizing ecofriendly. It also has two methods to create electric power from sunlight. One is by using photovoltaic cells. It is manufactured using the essential component of silicon, which gathers sunlight efficiently. A large number of silicon cells are arranged sequentially (titles form) to collect sunlight.

The second one is by using mirrors to produce heat, which is later used to heat the water into steam. These highly heated steam rotates the turbines and thereby gives electrical energy. A sample model of the solar energy system is depicted in Figure-1, where it can generate $1 \mathrm{~kW}$ to $10 \mathrm{~kW}$ of electrical power.

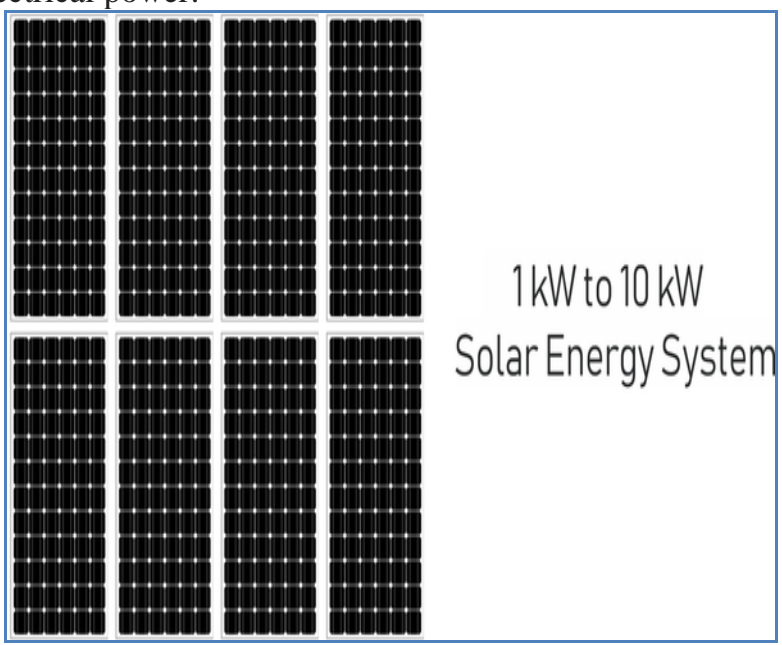

Figure-1. Solar Energy System
Advantages
$>$ The solar system is eco-friendly
$>$ Less service cost
$>$ No transmission cost
$>$ It is one of ideal remote source generates more power.
Disadvantages
$>$ Construction cost is high
$>$ Depends on weather conditions
$>$ Need high capacity batteries
$>$ Installation area needs to be large 


\section{Wind Energy System (WES)}

Wind energy is get converted into electrical energy by using windmills (WM). It consists of wind turbines, which turn wind energy into kinetic energy (KE). The $\mathrm{KE}$ rotates the induction generator and where the KE gets converted into electrical energy. The view of the wind energy system is depicted in Figure-2.

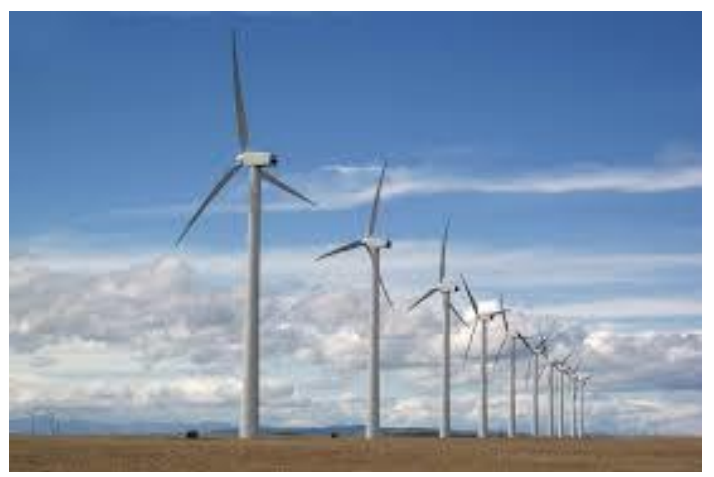

Figure-2. Wind Energy System

In WMs, a more significant number of wind turbines are arranged in an array form (row, column, and matrix). The distance between the wind turbines should be considered and needs to be maintained, avoiding contact between one another. The direction of the windmill installation should face the direction of wind flow. It is also installed remotely (far away) from city and height locations.

\section{Advantages}

$>$ Wind energy is free.

$>$ And therefore, it provides uninterrupted power generation.

$>$ Once the wind plant gets installed, there is no service/maintenance cost.

\section{Disadvantages}

$>$ Installation cost is high

$>$ It cannot generate the same amount of electricity always

$>$ It needs un-interrupted wind

$>$ Provides noise disturbances

$>$ Needs a plane without trees and buildings.

\section{Hydro Energy System}

The HES is a method to convert the river or ocean water into electricity. This HES works on the principle of gravitational force.

It is mainly constructed in water dams or reservoirs. While the water flows down, it rotates the turbine towards the penstock and thus provides KE, which converts into electric energy. A sample hydro energy system is depicted in Figure-3.

Advantages
After a successful power generation, water can be reused.

$>$ A construction hydropower plant is a long-life system. (equal to the age of water dam)

$>$ Less service cost

$>$ No fuel cost for operating the system

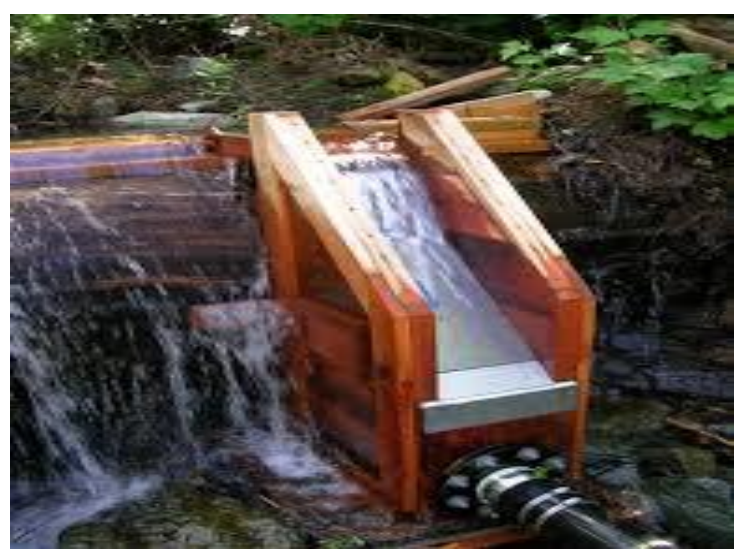

\section{Disadvantages}

Figure-3. Hydro Energy System

$>$ Setup cost is high

$>$ It works only rainy season

$>$ Need long transmission lines for power transmission.

\section{Hybrid Energy System}

More than one renewable energy resources combine into the energy generation system is called a hybrid energy system. It is developed to overcome today's energy crisis by combing them into an energy network like a grid system. Since the non-renewable resources are limited in nature,the electric industry is motivated to go for a hybrid energy system. A hybrid energy system can provide sufficient energy by combining two or more renewable energy sources. Individual renewable energy sources can not provide continuous energy for all the natural climate conditions. A sample hybrid energy system is illustrated in Figure-4.

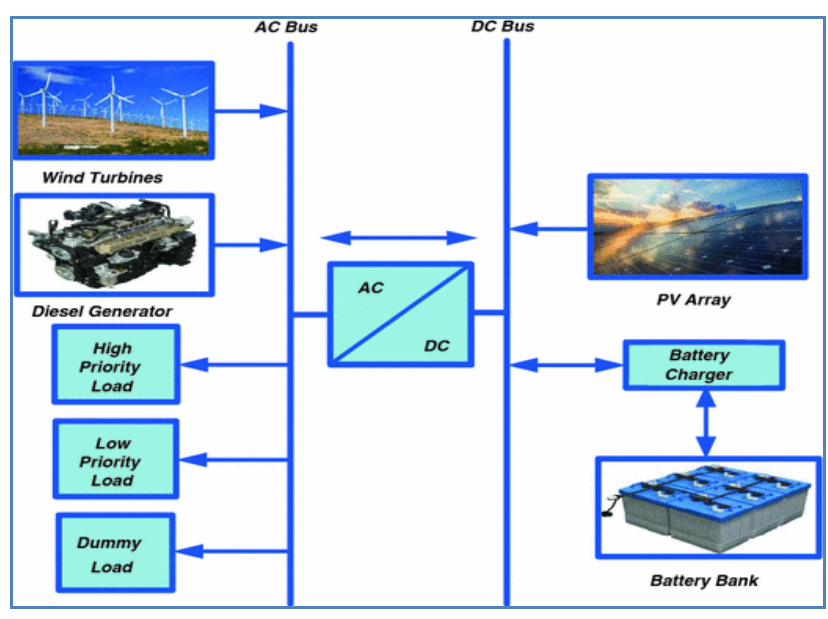

Figure-4. Hybrid Energy System 
In the hybrid system,the solar, wind, and the diesel generator are the renewable energy sources interconnected to produce more energy to fulfill the end-users' energy demand. Each seed generated power depending on the natural effects such as rain, wind, and sunlight. On rainy days solar can not generate the required amount of power. On sunny days, windmills can not generate the necessary amount of power, like a hydropower plant. Hence by combining more renewable energy sources, the user demand is fulfilled by developing more capabilities continuously.

From the above discussion, it is clear that, due to more population and their high demand for electric power, it is essential to fulfilling it by generating more power continuously. Hence, a hybrid energy system is preferred for continuous and reliable power generation for end users. A hybrid energy system can be incorporated into a grid, DG, and other electric networks.

\section{Literature survey}

This section presents a set of earlier research methods focused on energy generation using hybrid renewable energy sources. They faced various issues and challenges in solving optimal power flow, etc. For understanding the problems, it is necessary to study and understand the earlier research works. For example, the authors in [1] proposed utilizing renewable energy resources more efficiently than the other models. The genetic algorithm has been implemented for optimizing the power flow in hybrid renewable energy sources.

The authors in [2] developed a novel storage model of renewable energy sources, mainly focused on saving energy. Store efficiently, a lead-acid battery has been used in the experiment. It primarily focused on charging and discharging speed. There are various methods used for obtaining hydrogen from solar power. The most common way for hydrogen production is to get hydrogen from the water at low temperatures through electrolyzing. The solar hydrogen fuel-cell hybrid energy systems are used to store different forms of energy [3].

The author in [4] proposed a multi-objective optimization algorithm for selecting optimal renewable energy sources to increase the power generation. The main scope of the work is to diminish the cost, emission elimination, optimizing the voltage. The improved honey bee mating algorithm corrects the multi-objective optimization. The authors in [5] proposed a multi-objective method for hybrid renewable energy systems by using evolutionary algorithms. The scope is to optimize hybrid systems by using various optimization algorithms. Also, those algorithms have extended by using genetic, particle swarm optimization algorithms for obtaining optimal results. Hybrid renewable energy systems are becoming more common for remote areas due to recent technical advances in renewable energy. In [6], the author proposed various methodologies for hybrid renewable energy resource selection, design, and process. The proposed method shows the hybrid PV/wind turbine systems are becoming more common. Also, the issues are highlighted for hybrid systems.
From the above discussion, it is clear and noticed that hybrid renewable energy systems are normally good at generating more power. But choosing renewable energy sources under various conditions according to the application is necessary. Hence this paper discusses a multi-objective optimization method for selecting hybrid renewable system configurations for reducing the cost, fuel with more power generation.

\section{Proposed Model}

The multi-objective model creation of hybrid renewable energy source features mixed variables, non-linearity, and optimal selection. It can adopt the appropriate resource based on the environmental conditions and demand for energy.

The flow of energy in the proposed hybrid renewable energy system is illustrated in Figure-5. It has two modes as the model I and model II. Model-I is individual, and model II is connected to the grid.

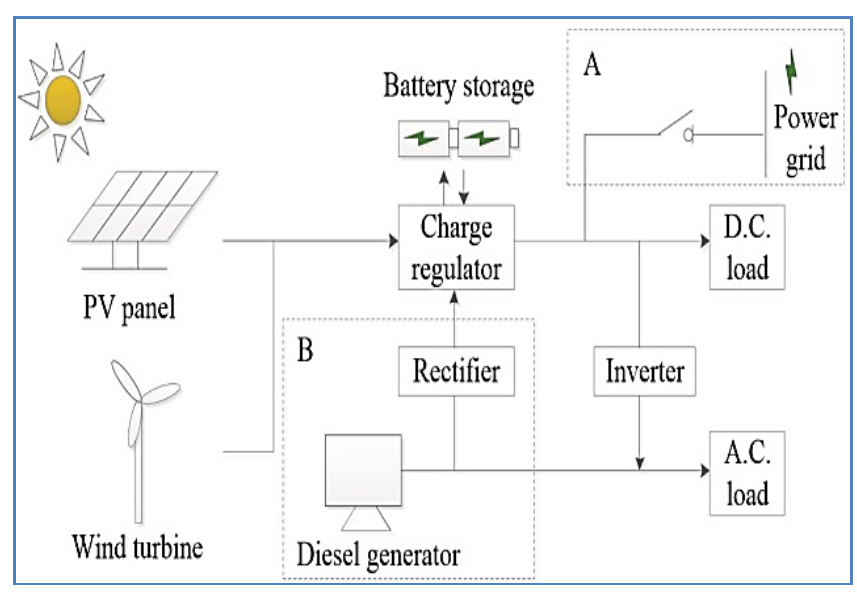

\section{Figure-5. Proposed Hybrid Renewable Energy System}

In this paper, Model-I aloneis considered. In Model-II, the amount of energy generated is larger than the demand during the energy generation, and it charges the batteries maximumly. The extra power generated is an additional profit to the electric industry. In Model-I, the renewable energy system is isolated and not linked with the grid, and it is shown as part A in Figure-5. The energy generated from renewable energy sources such as solar and wind is transmitted as DC load and flows to AC load through the inverter. Combining these energies provides a high amount of energy than the total demand by the end-user. So, after supply to the end-user, the remaining power is stored in the batteries for future use. If the hybrid energy system does not satisfy the demand, it will be discharged according to the SOC. In the case of unmet load, then the diesel generator is used for emergency power generation.

The multi-objective evolutionary algorithm has initialized a population with vectors, neighbor size, and maximum generations. For each solution, it compared with the 
neighbor value based on Euclidian distance and chose the vector. Each time the individual solution is reached with various conditions and obtain the best one.

\section{Power Optimization}

In the overall HRES, the solar (PV) plant is considered primary since it has no pollution and is safe. The PV array comprises of $\mathrm{N}$ number of panels arranged as an array $\mathrm{Np}$, used for increasing the output power, and it can be calculated using the following formula as:

$\boldsymbol{P}_{p v}=F_{\text {loss }}{ }^{\circ} N_{s}{ }^{\circ} N_{p}{ }^{\circ} I_{p v}{ }^{\circ} U_{p v}$

In the above equation, $P_{\mathrm{pD}}$ denotes the number of panels,

$F_{\text {loss }}$ is the power loss, the product of $N_{g}$ and $\mathbb{N}_{p}$ are used to obtain Npv. The electric current generated is $I_{p v}$ And voltage is $U_{p v}[7]$.

In the case of a wind turbine, it comprises of tower, generator. The output power obtained from the wind turbine is calculated using the following formula as:

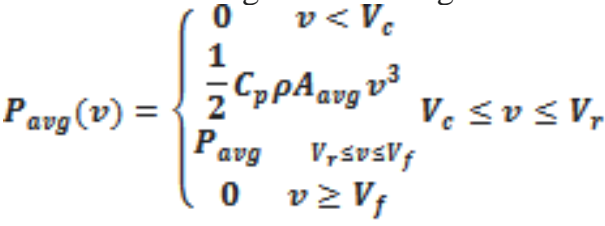

$v=V_{r}\left(\frac{H_{\text {avg }}}{H_{r}}\right)^{1 / 7}$

In the above equation $C_{\mathrm{p}}$ represents the coefficient for the

maximum amount of wind power. The total real power is divided by the turbine power. The notation $A_{\text {avg }}$ represents

the rotor cross-section, and $\rho$ is the density of the air and

represents the power rated from windmills. The cut-in, cutoff, of velocity and rated are described using $V_{c^{v}} v_{s}$ and $V_{r}$

respectively. The main objective of this paper is to cost optimization, and it can be written as:

$C_{s}=C_{\text {intitial }}+C_{\text {fuel }}+C_{\text {replace }}+C_{\text {repair }}+C_{\text {replace }}$

The main objective is written as $\min (F)=\min \left(C_{,}, F e, P u\right)$ for the isolated island mode

Under the conditions of

$H_{\text {low }} \leq H_{\text {avg }} \leq H_{\text {high }}$
$S O C_{\min } \leq S O C(t) \leq S O C_{\max }$

$P_{\text {bat }}^{\min } \leq P_{\text {bat }}(t) \leq P_{\text {bat }}^{\max }$

$\mathbf{0} \leq \boldsymbol{P}_{d g} \leq \boldsymbol{P}_{d g r}$

The above optimization process under various constraints, such as increasing power generation, reducing cost, reduce fuel cost, and diminish the loss. The overall process is implemented and experimented on benchmark data. Before start implementation, some of the parameters are set to solve the above equations. Table -1 shows the initial cost and repair cost for the entire system.

Table-1. Cost per unit and repair cost

\begin{tabular}{|l|l|l|l|l|l|l|l|}
\hline Cost & $\begin{array}{l}\mathrm{P} \\
\mathrm{V}\end{array}$ & $\begin{array}{l}\text { Win } \\
\mathrm{d}\end{array}$ & $\begin{array}{l}\text { Tow } \\
\text { er }\end{array}$ & Bat & Gen & $\begin{array}{l}\text { Invert } \\
\text { er }\end{array}$ & $\begin{array}{l}\text { Rectifi } \\
\text { er }\end{array}$ \\
\hline $\begin{array}{l}\text { Initia } \\
\text { 1 cost }\end{array}$ & $\begin{array}{l}30 \\
0\end{array}$ & $\begin{array}{l}300 \\
0\end{array}$ & $\begin{array}{l}250 / \\
\mathrm{m}\end{array}$ & $\begin{array}{l}12 \\
6\end{array}$ & 1514 & 240 & 225 \\
\hline $\begin{array}{l}\text { Repa } \\
\text { ir } \\
\text { cost }\end{array}$ & 30 & 50 & $\begin{array}{l}2.5 / \\
\mathrm{m}\end{array}$ & $\begin{array}{l}1.2 \\
6\end{array}$ & $\begin{array}{l}0.17 / \\
\mathrm{h}\end{array}$ & 12 & 8 \\
\hline
\end{tabular}

Table-2.

ParameterSetting

\begin{tabular}{|cccccc|}
\hline Parameter & Value & Parameter & Value & Parameter & Value \\
\hline$F_{\text {loss }}$ & 0.73 & $A_{\text {wg }}\left(\mathrm{m}^{2}\right)$ & 12.59 & $S O C_{\max }$ & 1 \\
$V_{c}(\mathrm{~m} / \mathrm{s})$ & 4 & $P_{\text {wgr }}(\mathrm{kW})$ & 1 & $P_{\text {dgr }}(\mathrm{kW})$ & 2 \\
$V_{r}(\mathrm{~m} / \mathrm{s})$ & 14 & $H_{r}(\mathrm{~m})$ & 10 & $\gamma_{1}(\mathrm{~L} / \mathrm{kWh})$ & 0.08 \\
$V_{f}(\mathrm{~m} / \mathrm{s})$ & 20 & $C_{\text {bat }}(\mathrm{Ah})$ & 100 & $\gamma_{2}(\mathrm{~L} / \mathrm{kWh})$ & 0.25 \\
$C_{p}$ & 0.4 & $V_{\text {bat }}(\mathrm{V})$ & 12 & $E_{f}(\mathrm{~kg} / \mathrm{L})$ & 2.5 \\
$\rho\left(\mathrm{kg} / \mathrm{m}^{3}\right)$ & 1.29 & $S O C_{\min }$ & 0.2 & $C_{\text {unifue }}(\$ / \mathrm{L})$ & 1.2 \\
\hline
\end{tabular}

All the parameters used in the hybrid renewable energy sources are obtained from the implementation and given in Table-2.Some of the parameters are the radiation intensity of the solar, velocity, the temperature of the wind environmentis collected for one year, and used in the experiment. Most of the parameter values are assumed as constants; it never changed for a defined time interval.

The entire procedure of the multi-object evolutionary algorithm is executed with a population size of 100 , and the number of executions is 50 . The conditions of all the six parameters, such as Npv, Navg, Nbat, Ndg, Havg, and alpha, are assigned as a row vector and considered as a single candidate solution. The peak period of the electricity generation is used for data collection used in the experiment. The total amount of time (in hours) is (T) in a year used in the investigation is calculated using the following equation as:

$T=24 x 365=8760$ 
The cost calculation, according to the parameters, is given in Table-3.

Table3. Cost Calculation

\begin{tabular}{|l|l|}
\hline Solution & Cost $($ Cs in \$) \\
\hline 1 & $12,984,512$ \\
\hline 2 & $12,192,458$ \\
\hline 3 & $10,002,348$ \\
\hline
\end{tabular}

From the table-3, it is clear that the proposed model obtained less cost. This experiment aims to meet the $100 \%$ of energy demand and restrict the emission lesser than $2500 \mathrm{~kg}$ with $\mathrm{Pu}=0 \%$, and $\mathrm{Fe}$ is less than 250. From the solutions, the less cost obtained is given in the table.
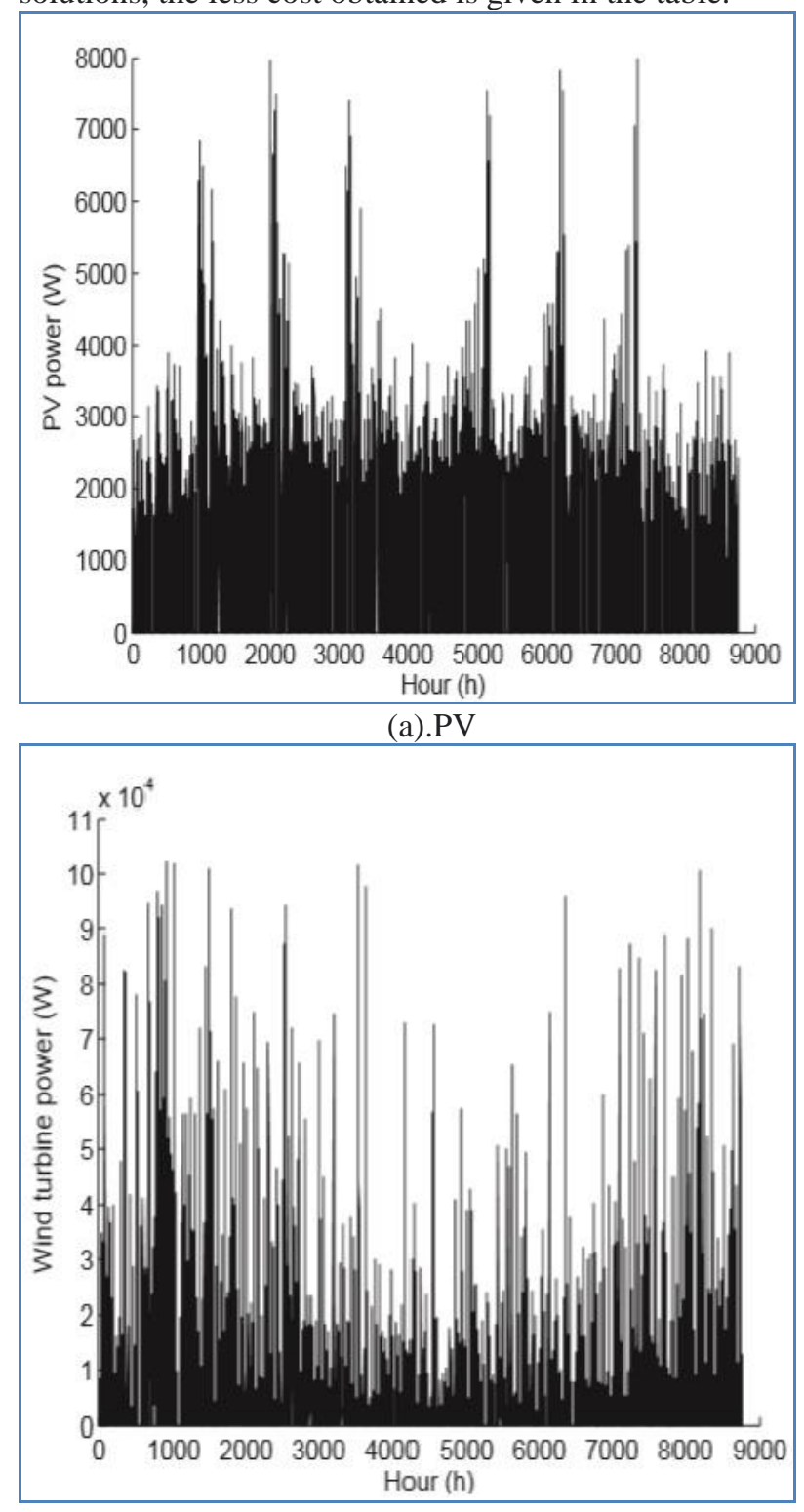

(b). Wind Generator

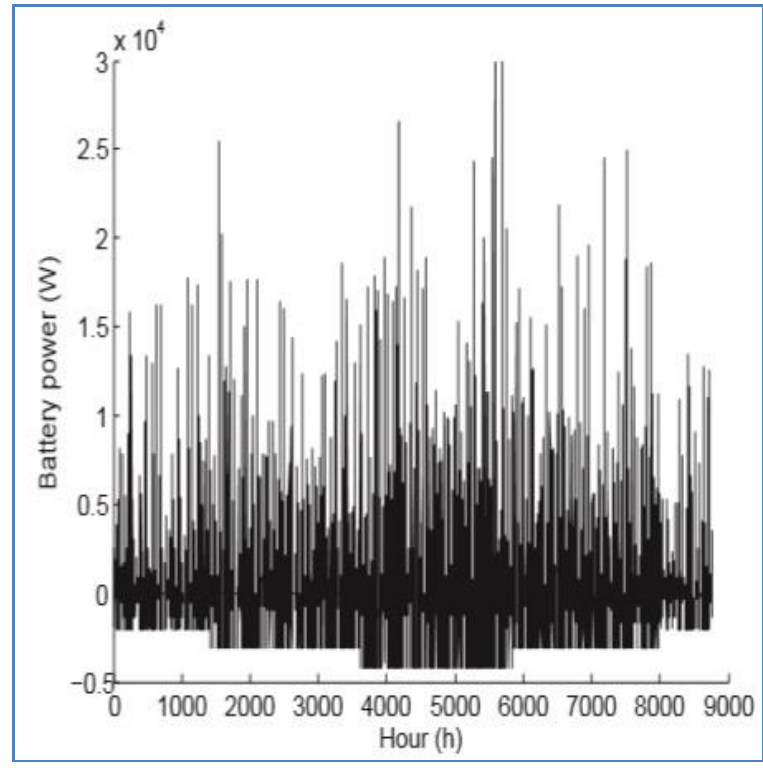

(c). Battery

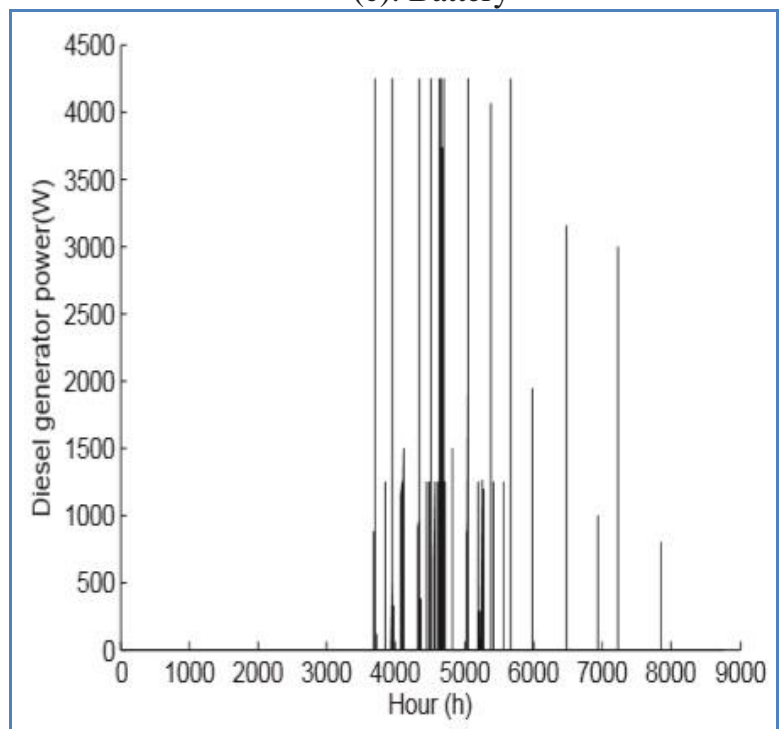

(d). Diesel Generator

Figure-6. Amount of Power Generated from Various Renewable Energy Resources

Based on the obtained results from the optimally selected hybrid renewable resource configurations. The power supply for the defined time interval from the chosendesign is given in Figure-6(a) to Figure-6(d). It shows the power generated using PV, Wind, Battery, and diesel generators, respectively.

\section{Conclusion}

The main objective of this paper is to improve the power generation optimally based on multi-objectives. Multiple purposes and conditions are defined in the equation and solved by the evolutionary algorithm. The proposed model is implemented in MATLAB software, and the results are verified. A random population and the corresponding parameter values are generated randomly, and the experiment is executed iteratively to obtain the optimal solution in terms of power generation and cost reduction. 


\section{References}

[1]. Zeng, M. Li, J. F. Liu, J. Wu and H. W. Ngan, "Operational optimization of a stand-alone hybrid renewable energy generation system based on an improved genetic algorithm," IEEE PES General Meeting, Providence, RI, 2010, pp. 1-6, DOI: 10.1109/PES.2010.5589885.

[2]. M.K.Deshmukh and S.S.Deshmukh (2008)," Modeling of hybrid renewable energy systems," Renewable and Sustainable Energy Reviews, Vol. 12, No. 1, January 2008, PP. 235-249.

[3]. A.Yilanci, I.Dincer, H.K.Ozturk, (2009), "A review on solar-hydrogen/fuel cell hybrid energy systems for stationary applications," Progress in Energy and Combustion Science, Vol. 35, NO. 3, June 2009, PP. 231244.

[4]. TaherNiknam, Seyed ImanTaheri, JamshidAghaei, SajadTabatabaei, MajidNayeripour, (2011), "A modified honey bee mating optimization algorithm for multi-objective placement of renewable energy resources," Applied Energy," Vol. 88. No. 12, PP. 4817-4830.

[5]. M.Fadaee and M.A.M.Radzi, (2012), "Multi-objective optimization of a stand-alone hybrid renewable energy system using evolutionary algorithms: A review," Renewable and Sustainable Energy Reviews, Vol. 16, No. 5, June 2012, PP. 3364-3369.

[6]. M.K.Deshmukh and S.S.Deshmukd, (2008), "Modelling of hybrid renewable energy systems," Renewable and Sustainable Energy Reviews,Vol. 12, No. 1, January 2008, PP. 235-249.

[7]. R. Sathish, R. Manikandan, S. Silvia Priscila, B. V. Sara and R. Mahaveerakannan, "A Report on the Impact of Information Technology and Social Media on Covid-19," 2020 3rd International Conference on Intelligent Sustainable Systems (ICISS), Thoothukudi, India, 2020, pp. 224-230, doi: 10.1109/ICISS49785.2020.9316046.

[8]. Manikandan, R and Dr.R.Latha (2017). "A literature survey of existing map matching algorithm for navigation technology. International journal of engineering sciences \& research technology", 6(9), 326-331.Retrieved September $15,2017$.

[8]. Shi. Z et al. (2015), "Multi-objective optimal design of hybrid renewable energy systems using the preferenceinspired coevolutionary approach," Sol. Energy, 2015, 118, 96-106. 